\title{
THEORETICAL ECOLOGY AS ETIOLOGICAL FROM THE START
}

\author{
AUthor REMOVED FOr REVIEW
}

\begin{abstract}
The world's leading environmental advisory institutions look to ecological theory and research as an objective guide for policy and resource management decision-making. In addition to the theoretical and broadly philosophical merits of doing so, it is therefore practically significant to clear up confusions about ecology's conceptual foundations and to clarify the basic workings of inferential methods used in the science. Through discussion of key moments in the genesis of the theoretical branch of ecology, this essay elucidates a general heuristic role of teleological metaphors in ecological research and defuses certain enduring confusions about work in ecology.
\end{abstract}

\section{KEYWORDS}

History and Philosophy of Ecology; Theoretical Ecology; Teleology

As ecology is the science of complex biophysical dynamics directly relevant to environmental policy and resource management decision-making, advisory institutions around the world have increasingly emphasized the guiding role the science should play in such decision-making. Indeed, ecology is now seen as an objective guide for "urgent political, ethical, and management decisions about how best to live in an apparently increasingly-fragile environment” (Colyvan et al, 2009, p. 1).

This is reflected in countlessly many regional, national, and international directives and pieces of legislation that call to protect ecological entities (e.g. ecosystems), their functionality (e.g. stability), and properties (e.g. biodiversity) (REMOVED FOR REVIEWb). For example, the U.S. Environmental Protection Agency (EPA), European Union, and National Resources Canada each emphasize 'long-term sustainability of ecosystem's structure and functioning' as an overarching guide for all policy and management strategy decision-making (cf. Apitz et al, 2006; McAfee \& Malouin ed., 2008; McFadden \& Barnes, 2009; McGinty et al, 1995). And one finds many explicit normative claims about ecological entities in the expanding literature on mitigating losses of human 
goods (e.g., agricultural species and human health benefits) due to climate change (see REMOVED FOR REVIEWb). For instance, the United Nations Framework Convention on Climate Change 2013 analysis of non-economic losses lists loss of "ecosystems," “ecosystem services" (goods dependent on the ecosystem functionality), and "biodiversity" (an ecosystem property), as the "main types of non-economic losses" that will be experienced due to climate change (UNFCCC, 2013, p. 4).

Explicit claims that environmental policy-makers and resource managers should consult ecological theory as an objective guide for decision-making are also easy to find. For example, the EPA's general resource management guidelines emphatically state that efforts to protect any particular natural ecosystem should be guided by "the latest scientific understanding of the inherent properties (i.e., patterns and processes) of that ecosystem type” (2002, p. 78). Leading ecologists even straightforwardly promise that ecological theory can serve as "a strong guide for environmental management and resource conservation” (Jørgensen, 2006, p. 21).

At the same time, critics of ecology-guided policy continue to contend that such promises ring empty and warn that advisory organizations have been foolhardy to embrace ecological theory as a guide for decision-making-on the grounds that the science has shaky philosophical foundations (see Sagoff 2013 for recent arguments). Many have questioned whether the entities described in ecological theory exist in any meaningful sense at all (see Jordan, 1981; Sagoff, 1997; Shizas \& Stamous, 2010; Sterelny, 2001; Wittbecker, 1990). ${ }^{1}$ And numerous authors have argued that theoretical ecological research is empirically unfounded (even empirically unfoundable), and contend that directives advising one to look to it for guidance in policy and management decision-

\footnotetext{
${ }^{1}$ I am sympathetic to the view that many concepts employed in ecology (e.g. 'ecosystem' and 'community') can, and arguably do, serve as useful and practically valuable theoretical constructs even if they haven't any naturally delineated analogues; cf. Fitzsimmons, 1999 and O’Neill, 2001.
} 
making are therefore deeply problematic (cf. Hall 1988; Haskell 1940; Peters 1991; Sagoff 2003; Sagoff 2013).

Of course, ecology's critics are right that it is advisable to recognize the limitations of theories and research methods employed in the science. To best understand those limitations and how ecological research may be useful for practical decision-making despite them, it is also crucial to clear up confusions about ecology's conceptual foundations and to clear away misguided critiques that engage such confusions. Numerous philosophers and ecologists have attempted to flesh out a reasonable metaphysics and epistemology of ecology with the aims of:

contributing to ecology itself by working toward a unifying theoretical foundation; exploring the implications of inferential methods used in ecology for philosophy of science in general;

better understanding potential applications of research processes used by ecologists; and defending the science against misguided criticisms (see, for example, Cooper 2007; Eliot 2011; McIntosh 1985; Odenbaugh 2011b, Reiners \& Lockwood 2010).

Many confusions about ecology's philosophical foundations stem from the absence of a straightforward narrative of the genesis and evolution of thinking in the science. So, an approach that has been fruitful in philosophical work on ecology has been to show light on conceptual innovations that brought the science to its current form through analyses of key research projects in its historical development (see REMOVED FOR REVIEWa; de Laplante \& Picasso 2011; Golley 1993, Odenbaugh 2007; Odenbaugh 2011a; Ulanowicz 1999). This essay employs this jointly historical and analytic approach to clarify certain inferential methods used in modern ecology and clear away a class of persisting confusions about the science's conceptual foundations.

In $\$ 1, I$ discuss major innovations in early ecologists' thinking about the nature of ecological entities that I contend mark the historical beginning of modern ecology. I then examine the role of teleological characterizations in modern ecology. That is, characterizations of ecological 
populations, communities, or systems, as 'goal-directed' or as 'functioning toward some goal state.' In $\$ 2$, I elucidate a general epistemic role of such characterizations through discussion of seminal ecologist G. Evelyn Hutchinson’s paper “Circular Causal Systems in Ecology” (1948), which I place as the first, and in certain ways archetypal, theoretical research project in modern ecology. I argue that Hutchinson (1948) does not use teleological characterizations of ecological phenomena literally but as metaphors that aid in developing "mechanistic," component-to-component, accounts of the underlying causes of observable ecological network-level dynamics. I support this reading by offering an operational account of the heuristic role teleological metaphors play in the reasoning process he employs in his landmark paper. I contend, moreover, that ecologists have apparently followed Hutchinson, and typically use teleological characterizations as metaphors that play heuristic roles in advancing understanding of the underlying mechanics of ecological network-level phenomena.

In $\$ 3, I$ then further defend my position and critically respond to opposing literalist construals of teleological characterizations in ecology_-including arguments according to which theoretical ecological research is unscientific, and allegedly of no value for practical decision-making, because it is supposed to rely on teleological, "magical," thinking (Sagoff, 2013, p. 248). I support my contention that robust teleological views are not and have not been embraced as a mainstream convention within ecology since Hutchison (1948) at least, by pointing to textual evidence showing that ecologists have stayed on board with the idea that teleological characterizations are not literal but instrumentally useful metaphors. I then show that ecologists can block claims that their functional accounts of ecological phenomena rely on commitments to a robust teleology by outlining a deflationary, etiological and instrumentalist, view available to them. In essence, in stark contrast to a teleological metaphysics that accepts "top-down" causality, the endorsed 'etiological' 
view sees teleological characterizations as shorthand ways of describing the complex component-tocomponent, "bottom-up" or "efficient," causes of ecological network-level properties.

\section{Time-stamping The Birth of Modern ECology}

While I cannot deny that some ecologists embrace robust teleological metaphysics, I will establish that this commitment is not relied on within modern theoretical ecology-as some authors would have one believe. Since I will begin to establish this by discussing key moments in the historical genesis of modern ecology and the subfield theoretical ecology, it is sensible to begin by pinning down when modern ecology began. As I understand the history of ecology, modern ecology began when, in certain well-known works, ecologists traded ontologically robust ideas of populations, communities, and ecosystems, for a more ontology-neutral view according to which ecological entities are contingent causal networks resulting from species-typical interactions between organisms and components of their shared environment(s) (REMOVED FOR REVIEWb).

Despite the fact that ecologists still use language that can easily elicit misinterpretations of their ontological commitments, the ecological literature shows that this more neutral view has been the received view for a long time. Some authors argue that Karl August Möbius articulated this understanding of ecological entities as contingent causal networks in the 1800s, and others argue that the view took root even earlier (see, for example, Shrader-Frechette \& McCoy, 1993, p. 19; Egerton, 2012, Ch. 1). I won't make heavy work of pinpointing the view's exact origin or tracking its genesis, since I wish to simply demarcate when modern ecology began by establishing when it became a widely received view.

In my view, three specific articles published in the 1940s ushered in the wide-spread acceptance of the salient network-based view, and stimulated the growth of the theoretical branch of ecology by demystifying the holistic (“top-down”) study of populations, communities, and ecosystems. These are Raymond Lindeman's “The Trophic Dynamic Aspect of Ecology” (1942), A. 
B. Novikoff's “The Concept of Integrative Levels and Biology” (1945) and Hutchinson's "Circular Causal Systems in Ecology" (1948). I will now "time-stamp" the birth of modern theoretical ecology by outlining what Lindeman and Novikoff did in each of their papers to help usher in the modern era of ecology and then explaining why I place Hutchinson's paper as the first work in modern theoretical ecology.

In essence, Lindeman (1942) first explicitly described community and ecosystem-level dynamics as the product of complex series of ecological interactions-what he calls "physicalchemical-biological processes" - in a paper published in a popular academic journal (cf. Golley, 1993, Chaps. 3 and 4). ${ }^{2}$ So, Lindeman helped popularize the networked-based view simply by explicitly describing ecological entities as biophysical networks in his widely read and cited paper. Still, in my view, Lindeman did not do enough in the way of articulating how community and ecosystem dynamics can be produced to count the work as having firmly established the networkbased view. Lindeman (1942) does not explain in what the "physical-chemical-biological processes" that he claims produce network-level dynamics can consist, but only draws correlations between changes in environmental factors (e.g., global temperature and nutrient levels) and changes in the relative abundances of monitored populations. In fact, explaining how the complex processes that Lindeman describes can produce ecological network-level properties requires a more complete theory of biochemistry than Lindeman and most ecologists at the time were working with.

\footnotetext{
${ }^{2}$ Some may complain that I have unfairly overlooked earlier works in which ecologists seem to discuss ecological phenomena in network-based terms. For example, Elton (1927) and Tansley (1935) both discuss ecological communities and "systems" in terms of trophic interactions and "webs"; see REMOVED FOR REVIEWb. As an anticipatory response, I submit that substantive claims made in earlier works I know of are roughly the same as Lindeman's, in that they are too vague to warrant concluding that their author's understood ecological entities as natural causal networks in the way modern ecologists do. I also think there is a reasonable case to be made that noteworthy ecologists working in the mid-1920s and 1930s (namely Elton and Tansley), embraced more thoroughgoing antirealist views. More to the point of my overall argument, remember also that I am here concerned with outlining what was done in those works that effectively "ushered in the wide-spread acceptance of the salient network-based view"; and, in my view, earlier works just didn't do this because the view was not generally accepted until later, in the 1940s and 50s.
} 
To describe the sorts of causal interactions that can realize the "physical-chemical-biological processes" Lindeman claimed produce community and ecosystem-level dynamics, one must explain how trophic interactions, environmental factors, and network-level dynamics are causally related. Although George Verdanksy developed the central ideas of biochemistry needed to make the relevant connections by the 1930s, they were not employed by anyone in the ecological literature until Hutchinson used Verdansky's biochemical theory to develop accounts of community and ecosystem mechanics after the publication of Lindeman's paper (see Hutchinson, 1979, p. 233). So, while Lindeman certainly helped popularize the network-based view, his 1942 paper cannot be counted as the work that marks the beginning of a new, modern, era in ecology, because he did not describe how ecological network-level dynamics may occur.

Though Novikoff (1945) also fails to provide a causal account of how ecological networklevel properties are produced, he made a more significant stride in demystifying the holistic study of ecological networks than Lindeman, because, unlike Lindeman, Novikoff explicitly discusses what the right metaphysics of ecology should and should not entail. Specifically, Novikoff explains the network-based view and points out that it does not entail commitments to broadly 'organicist' metaphysical theses endorsed by earlier ecologists. In essence, according to those organicist views Novikoff rebuffs, nature is supposed to be comprised of complex wholes whose constituent biological parts are unified, comprise an organic whole, by exhibiting behaviors that are coordinated to sustain vital processes of the whole complex of them (see, for example, Clements, 1916). In other words, earlier, organicist, ecologists attributed irreducible causal properties to ecological networks.

Novikoff argues that there is a sensible holistic view that does not entail a commitment to the existence of irreducible, "emergent," causal properties of the networks ecologists study. He explains that this network-based view is still holistic in the sense of taking account of ecological network-level properties, but that it does not entail treating network-level properties as causal properties 
of the networks themselves that are ontologically irreducible to series of interactions between their constituent parts. In his words:

Each level of organization possesses unique properties of structure and behavior which, though dependent on the properties of the constituent elements, appear only when these elements are combined [to comprise networks]. Knowledge of the laws of the lower level is necessary for a full understanding of the higher level; yet the unique properties of phenomena at the higher level cannot be predicted [...] from the laws of the lower level. $\left(1945\right.$, p. 209) ${ }^{3}$

Novikoff claims that taking account of "higher level" properties and regularities ("laws") is necessary for understanding ecological networks-perhaps even an epistemic necessity. However, he does not endorse the idea that ecological networks bear irreducible causal properties that are operative in coordinating the behaviors of their component parts. In fact, in his paper, Novikoff only commits to the metaphysical claim that network-level properties are existentially dependent on those of their “constituent elements," and are "a consequence of their [i.e., their parts'] properties" (ibid.). Notably, this claim is theory neutral in that it is compatible with both realism and antirealism, or "reductionism," about individual ecological entities and with both realism and antirealism about ecological types.

Accordingly, Novikoff (1945) argues that the network-based view is metaphysic-neutral. As he explains it, the view: "neither reduces phenomena of a higher level to those of a lower one, as in mechanism, nor describes the higher level in vague non-material terms which are but substitutes for understanding, as in [organicism]" (p., 209). The view does not "reduce phenomena of a higher level," in the sense that any actual network-level properties can only be seen by attempting to assess ecological networks as wholes. In my view, this is for the simple reason that network-level properties are abstract ways of characterizing complex series of (direct and indirect) component-tocomponent causal interactions between organisms (REMOVED FOR REVIEWb). Such properties

\footnotetext{
${ }^{3}$ My ellipsis removes "a prior" from the quotation, as I believe it is unnecessary. I note this because my deletion may change the content of this passage in ways unapparent to me.
} 
cannot be seen by looking at organism-to-organism interactions, but only by "zooming-out," so to speak, to the network level of analysis. The network-based view does not 'describe the higher level in vague non-material terms,' like organicist holisms, as Novikoff says, because it does not entail commitment to any specific speculative views regarding the ontological reducibility or irreducibility of ecological networks. So again, the view is neutral regarding the (ir)reducibility of ecological networks (or, if you prefer, it's agnostic regarding the reality of causally operative network-level properties).

As regards the legacy of his paper, in it, Novikoff explicitly endorsed the network-based view, and argued that any ecological network-level properties that may be found in nature can be best understood by studying both component-to-component interactions and ecological networks as wholes, whether or not ecological network-level properties are causally efficacious "over-and-above" the collective efficacy of their constituent parts. He thereby effectively instated the ontologically neutral, network-based, view as metaphysical foundation for modern ecology. For this reason, I see Novikoff's 1945 paper as marking the beginning of modern ecology. However, I do not consider it the first work of modern theoretical ecology. This is because, although Novikoff (1945) effectively ushered out antiquated organicist metaphysical views and instated the network-based metaphysical foundation for modern ecology, in his paper, he does nothing in the way of engaging any methods characteristic of theoretical ecological research.

Indeed, as a rather short "white paper," published for a general academic audience in Science, Novikoff only makes the general points that I have just discussed and does not present any research findings or apply or develop any research methodologies. It was not until Hutchinson (1948) that an ecologist clearly embraced the network-based view and also employed general methods used in theoretical ecology (cf. Slack, 2011). Theoretical ecological research uses "theoretical principles, metaphorical analogies, and mathematical models" to produce and test explanatory and predictive 
hypotheses about "the assembly, structure, and emergent properties" of population, community, and ecosystem-level networks (Sagoff, 2003, p. 531). ${ }^{4}$ Hence, what gives Hutchinson (1948) all of the hallmarks of later theoretical work, and distinguishes the work from earlier, pre-modern, theoretical works, is the combination of doing these things while embracing the network-based view.

To be clear, I am not suggesting that the practice of using mathematical models to characterize complex inter-organism phenomena began with Hutchinson (1948). It is well known that this practice began earlier, with the development of population models, like Lotka-Volterra models, in the $1920 \mathrm{~s}$ and 30s. Yet, in the substantive theoretical works pre-dating Hutchinson (1948), it is never suggested that entities like communities and ecosystems are causal networks to be found in nature. As these earlier theoretical works were developed in a period of backlash against earlier organicist conceptions of ecological entities, their authors-most notably Lotka (1925), Volterra (1926), and Gause (1932)_adopted a more extreme view than the ontologically-neutral holism that appears in Novikoff (1945) and Hutchinson (1948) (see Cooper, 2007, Ch. 2.3). The authors of these earlier theoretical works bought into variety of dichotomous thinking that arose in the early 1900s, according to which ecologists had to either embrace organicist teleological metaphysics or altogether deny the existence of ecological entities, and embrace a sort of nihilism, in order to avoid the entailments of organicism.

Frederic Clements (1916) famously endorses the former view in speculating that each natural ecological community is a 'supraorganism,' or an "organic entity [...that] arises, grows, matures, and dies" and has a "life-history" like an individual organism (p. 16). Henry Gleason famously endorses the competing nihilistic view in The Individualistic Concept of the Plant Association (1917). Therein, he

\footnotetext{
${ }^{4}$ I have replaced Sagoff's use of 'systems' with 'networks' for two reasons. First, ecologists do not always purport to investigate the properties of ecological systems, while ecological research does consist in the more general endeavor of studying ecological networks and their components. Second, Sagoff uses 'ecosystem' to refer to ecological networks in general; rather than distinguishing populations, communities, and ecosystems as different sorts of ecological networksas I will to preserve substantive distinctions made within ecology.
} 
explicitly rejects Clements claims and argues that populations and communities are nothing but contingent collections of interacting organisms that continually change and do not exhibit any sort of observable network-level structure or dynamics (see Gleason, 1917 and 1939; Odenbaugh, 2007). Those ecologists who developed the basic elements of the theoretical approach to ecology that Hutchinson (1948) builds on followed Gleason.

In fact, in their works that Hutchinson (1948) cites directly, populations, communities, and ecosystems are not ever described as naturally occurring causal networks. In these works, 'population' is used as a mass term that is elliptical for 'individuals of a species in a place' and there is no mention of 'communities' accept when referring to "human communities" (see Lotka, 1925). Accordingly, in the salient pre-modern theoretical works, there is no mention of investigating natural 'ecosystems,' and 'system' is used almost exclusively to refer to conceptual systems—as in "abstract systems of description" or "systems of equations" (Gause, 1932). ${ }^{5}$

As I will explain more below, Hutchinson (1948) offers functional accounts of the series of causal interactions through which biota and abiota can comprise ecological networks and produce dynamic patterns observable in aggregate data on relative population and nutrient abundances. This doesn't appear an especially noteworthy contribution to ecology on its own. However, viewed in the historical context in which his work was introduced, one can see that by providing the salient accounts Hutchinson (1948) did two key things that solidified the network-based conceptual foundation for subsequent work in ecology and helped facilitate the subsequent development of the theoretical branch of ecology.

\footnotetext{
${ }^{5}$ Lotka (1925) refers to "biological systems" in a few places and to "network[s] of relationships that connect [...] closely living species" in one place (p. 137). However, his overall project consists in re-conceptualizing biological phenomena in wholly physical terms, and using mathematical models from physics to simulate small population-scale phenomena (e.g., yeast populations) to test whether those equations can accurately predict what occurs in the selected populations.

Although one could make the case that he held a metaphysic-neutral view, the standard interpretation of Lotka sees him as embracing a thoroughgoing antirealism according to which ecological entities are notbing-but theoretical machinery; see Kingsland (1995), p. 34.
} 
First, he gave new life to 'community' and 'ecosystem' concepts by describing such things neither as living organic wholes nor as mere abstract constructs, but as naturally occurring causal networks resultant from series of component-to-component interactions between organisms and inorganic materials. By demonstrating how seeing communities and ecosystems in this way can facilitate better understanding of the underlying mechanics of observable trends in aggregated data, Hutchinson effectively led ecologists out of the trenches of metaphysical disputes about ecological entities and onto advancing knowledge about the workings of natural ecological networks without getting bogged down in those deep metaphysical questions. ${ }^{6}$ Second, he gave credibility to theoretical approaches to ecological research by demonstrating, by example, how one can garner insights into the underlying mechanics of emergent network-level dynamics through the application of "theoretical principles, metaphorical analogies, and mathematical models."7

\section{Hutchinson and Teleological MEtaPhor in Theoretical Ecology}

I progress in this section by first explaining in a bit more detail what Hutchinson does in his landmark paper, and then explaining the basic elements of a reasoning process still commonly used in ecological research that he introduced therein. As the use of teleological metaphor is a key element in that reasoning process, I close the section by offering an operational analysis of the instrumental role of such metaphors in that process.

Hutchinson (1948) basically uses teleological metaphors to help generate accounts of the biophysical mechanics that could produce patterns observable in aggregate data of different sorts. Specifically, he provides accounts of the mechanics that could produce correlated dynamic patterns, what he calls "oscillations," observable in data on nutrient resource and species abundances and data

\footnotetext{
${ }^{6}$ This is not to say that ecologists stopped arguing about metaphysics; they still do. It is to say that those ecologists who followed Hutchinson, and advanced the theoretical branch, were not preoccupied with these questions in their works.

${ }^{7}$ Hutchinson also helped the theoretical branch of ecology grow because his career spanned the period between the first wave of math-based analytical approaches (in the 1920's) and the development of the methods used in theoretical ecological research (by the 1960’s); see Cooper (2007), Ch. 5; Fretwell (1975), p. 4; McIntosh (1985), pp. $275-9$.
} 
on the Earth's biosphere. Figure 1 (below) depicts the sort of "observable oscillating" to which Hutchinson refers. In this Figure I have also simulated the correlations between periodic changes in nutrient and population abundance levels that are typically seen in aggregated data on particular populations and nutrient resource levels for those populations.

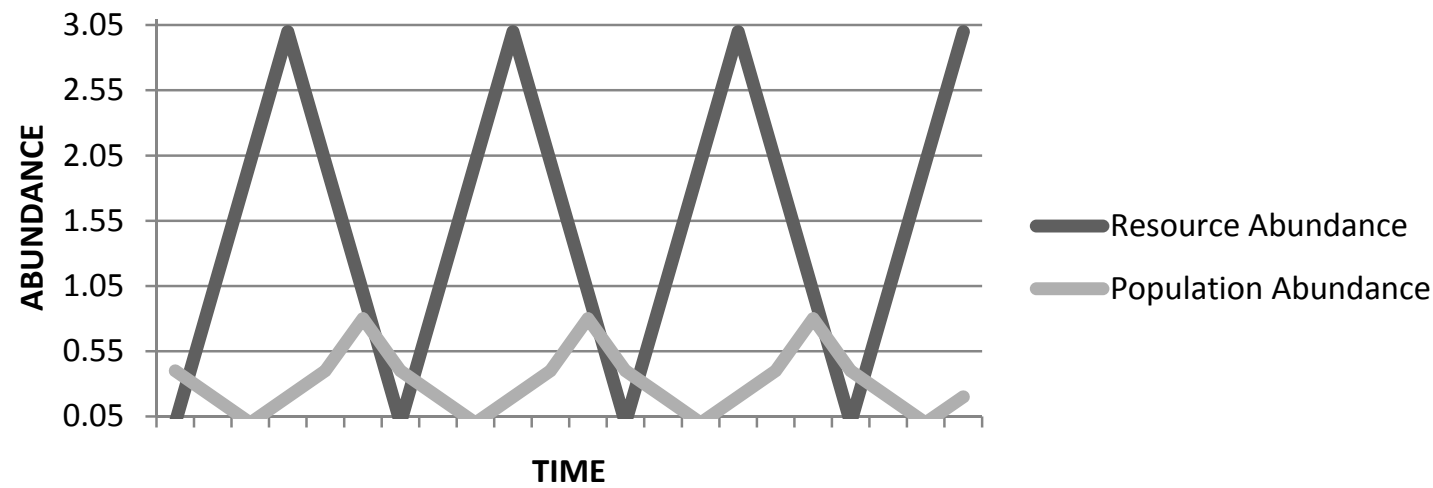

Figure 1: Conceptual Diagram of Nutrient and Species Abundance Oscillations ${ }^{8}$

To generate accounts of the biophysical mechanics that could produce correlated patterns like these, Hutchinson (1948) imagines that the relevant patterns result from "self-regulatory" processes within ecological networks and then conceptually constructs a feasible series of component-to-component interactions through which the organisms (i.e. the nodes) in an ecological network could instantiate such processes (1948, p. 237). In so doing, Hutchinson piloted the approach of using teleological metaphors as a conceptual instrument-a constraining heuristic or "frame"- to aid in the production of candidate accounts of the underlying mechanics of networklevel properties (cf. Peters, 1991, pp. 141-2).

Then, as I understand him, Hutchinson treated ecological networks and the biosphere as if they were self-regulating wholes whose constitutive parts exhibit coordinated behaviors in order to conceptually reconstruct how observable "cyclical" dynamics may be produced in such networks.

\footnotetext{
${ }^{8}$ Figure 1 is not derived from a data set, and I've made up the values. Still, the figure accurately illustrates the sort of correlated dynamics between resources and species to which Hutchinson refers. In fact, Figure 1 is very similar to datadriven figures found in works that Hutchinson references; in which the authors report correlations between resource (e.g., nutrient or prey) abundances and population (e.g., plant or predator) abundances; see, for example, Volterra (1926), Figs. I and II and Volterra (1927), Fig. 7. See also Clarke (1954), pp.396-9 and his Fig. 10.14.
} 
Unfortunately, Hutchinson does not explicitly say that this is what he is doing in his paper, and, as is the case with much of the contemporary ecological literature, one must take care to disentangle metaphorical language from substantive descriptive claims to correctly understand his work. Indeed, from the very start of his paper one confronts confusing, half-metaphorical, language, as Hutchinson explains that his understanding of ecological networks derives from mathematician Norbert Weiner's “cybernetic theory," according to which 'it is usual to find various teleological mechanisms acting to damp oscillations' within causal networks (p. 221). ${ }^{9}$

Despite the commitments that this borrowed terminology may suggest, careful reading shows that Hutchinson conceives of 'teleological mechanisms' in ecological networks as series of causal interactions that tend to keep the abundances of organisms and their environmental resources from fluctuating too extremely. In particular, he explains that such "mechanisms" are series of species-typical interactions that tend to keep population and resource abundances within ranges of fluctuation that allow multi-population, community-scale, ecological networks to persistby maintaining an overall organism-to-resource balance that enables their constituent populations to persist. So, according to Hutchinson, teleological mechanisms in ecological networks act like a thermostat in a heating system in a certain sense, in that they serve to keep such networks from changing so drastically they collapse (cf. Odum, 1959, p. 45). Still, the mechanical picture he presents is not one in which the behaviors of the component parts of ecological networks are somehow coordinated by an overall network control like a thermostat. To the contrary, he maintains that periodic cycles in nutrient and population abundances result from species-typical componentto-component interactions that can be usefully described both bio-geo-chemically ("in terms of the

\footnotetext{
${ }^{9}$ Hutchinson and Weiner were among several prominent figures to participate in the Josiah Macy "Feedback Conferences" in New York in the late 1940s; see Slack (2011), pp. 236-7. Weiner's hugely influential book Cybernetics, or Control and Communication in the Animal and Machine was also published in 1948-in the wake of that event. Notably, in it, Weiner explicitly abandons earlier teleological conceptions of physical systems; Evelyn Fox Keller (2008) provides an illuminating historiography of the abandonment of teleological thinking in science at this time.
} 
transfer of some substance through [a network]") and bio-demographically ("in terms of the variations in the numbers of biological units or individuals") (1948, p. 221).

Accordingly, in the first half of the paper, Hutchinson offers straightforward "bottom-up" accounts of series of typical biophysical interactions that he proposes produce carbon-cycling in the biosphere and of series of typical interactions that he proposes produce nutrient-cycling through ecological networks. He then argues that these series of typical component-to-component interactions are the "mechanisms" that jointly produce observable correlated changes and oscillations in nutrient and population abundances (1948, pp. 222-36). The latter part of his paper then concentrates on explaining how some theoretical population models (Lotka-Volterra model variations) can be used to predict relative rates of change in the abundances of certain sorts of interacting populations (e.g., predator and prey). And Hutchinson closes the paper by outlining how such models might be combined to generate useful community-scale models (1948, pp. 238-42).

For the purposes at hand, it is instructive to now turn to clarifying how teleological characterizations help ecologists better understand ecological phenomena. As I have said, I will do this by offering an account of the heuristic role that teleological metaphors play in the reasoning process that Hutchinson employed in his project and that ecologists commonly employ to date. That role of teleological metaphors in reasoning in ecology is brought into focus by looking at the role such metaphors play in sciences other than ecology.

Consider, for example, geophysicists descriptions of how riverbed structure typically evolves due to erosion from water flow as a bed's sediment material organizing so as to minimize the energy available to deform it by introducing resistance to flow (see, for instance, Eaton et al, 2006; Church et al, 1998). As another example, consider chemists descriptions of atoms of different types electrostatically attracting and repelling each other or their characterizations of the behaviors of aggregates of atoms in general as such aggregates always seeking "energetically favorable" 
combinations. Characterizations like these are to be interpreted metaphorically, because although they look as if they explain why the behaviors they are used to characterize occur prima facie, that information is not provided by such characterizations. Geophysicists are not saying that the sediment comprising a riverbed does not organize as it does because that sediment particle network has a goal to resist erosive forces. Likewise, chemists do not claim that aggregates of atoms organize as they do because they literally intentionally seek stable combinations. The teleological component of such characterizations is neither literal nor explanatory.

Rather, I submit that such metaphors aid in the process of understanding phenomena that are somewhat difficult to grasp by allowing them to be seen as similar to phenomena that are comparatively more familiar and therefore easier to understand. Accordingly, I submit that teleologically-charged notions like 'resistance,' 'attraction,' 'chasing,' and 'organizing' are useful metaphors because they help characterize the flow of causal processes that are relatively difficult to understand, and thereby aid scientists in generating causal accounts of how network-level dynamics occur. To illustrate how such metaphors do this, consider the following description of how salt (a network of sodium and chlorine atoms) dissolves in water presented by Marc Lange. Lange says:

The crystal lattice of sodium chloride [salt] is held together by very strong electrostatic attractions between alternating positively charged (sodium) and negative charged (chlorine) ions. In water, crystalline sodium chloride dissolves into individual sodium and chloride ions because the attraction between $\mathrm{Na}$ and $\mathrm{Cl}$ is greatly exceeded by the electrostatic attraction between $\mathrm{Na}$ and the partially negatively charged oxygen atom of a water molecule, and between $\mathrm{Cl}$ and one of the positively charged hydrogen atoms of the water molecule. Water molecules are therefore able to insert themselves between these ions; the energy needed to separate a $\mathrm{Na}$ atom from a $\mathrm{Cl}$ atom is more than provided by the energy released when bonds form between water molecules and these ions. (1994, p. 115)

In this passage, the teleological phrases indicate how, not why, the nodes in such atomic networks behave as they do. They are metaphorical, not unlike describing how individual clouds behave relative to one another by saying they "chase each other" or "dance together" across the sky (Nissen, 1983, p. 155). By helping one envision how the atoms comprising salt and water behave 
relative to one another to produce salt's dissolution, the metaphorical elements of characterizations like Lange's aid one, heuristically, in formulating a conceptual picture of the mechanics of how salt dissolves in water. I submit that Hutchinson's "teleological mechanisms," and more common talk of "self-regulation" and "self-organization" in ecology, also serve as heuristically useful metaphors, by outlining, in a cursory way, how the nodes in ecological networks must behave relative to each other to produce observable network-level properties.

In my view, Hutchinson's "teleological," "self-regulatory," mechanisms that "dampen oscillations" in population and nutrient abundances, are metaphors that helped him generate the component-to-component accounts of the series of interactions that could plausibly produce the observable correlated oscillations he sought to explain. Just as seeing atoms as attracting each other or clouds as chasing each other can be helpful, metaphors like 'self-regulation' are helpful by limiting the possibilities concerning what may serve as a plausible component-to-component account capable of explaining away the teleological content of such characterizations. Accordingly, these metaphors appear to serve constraining, heuristic, roles in Hutchinson's project by dictating that a plausible account of the underlying mechanics of observable oscillations in nutrient and population abundances must have organisms and their resource materials, the nodes in the networks that produce those oscillations, behaving in ways whereby they could collectively produce such patterned network-level dynamics. By providing accounts that fit this bill-his "biochemical" and "biodemographic" explanations of how observable oscillations in nutrient and population abundances are produced-Hutchinson (1948) effectively provides a way to explain away the teleological content of the metaphors he employs. His project at once shows how envisioning ecological networks as if they are self-regulating systems can help advance understanding of the inner workings of such networks, and exemplifies a general process of reasoning with teleological metaphors that is still commonly employed in ecological research. 


\section{Ecology as Etiological, not Teleological, in Its Metaphysics}

There has been a historied debate about whether ecology is ultimately undergirded by a teleological metaphysics in ecology and the philosophy thereof (de Laplante \& Picasso, 2011 provide a nice overview). For different reasons, some continue to urge that teleological characterizations of ecological phenomena are either best understood literally or somehow rely on unshakable teleological metaphysical commitments (see, for example, Goldsmith, 2008; Jax et al., 1998; ShraderFrechette, 1986; Voûte 1968; Worster 1990; Sagoff 2013). And, as I have said, some ecologists do in fact appear to wholeheartedly endorse robust teleological views. Though it is usually hard to tell how seriously committed individual ecologists may be, it is undeniable that ostensible commitments to teleological views are preserved through continued use of descriptions of natural ecosystems as exhibiting "self-organizing" tendencies and "top-down control" constraints that are said to partially determine the properties of their component parts (e.g., organism behaviors and traits) (see Sole \& Bascompte 2006). There are also enduring criticisms of ecology that engage a literalist construal of ecologists' teleological characterizations.

Numerous critiques presume that ecologists generally embrace a sort of "naïve positivism" and purport to provide literal characterizations of natural kinds of ecological phenomena (ShraderFrechette \& McCoy, 1993, p. 149; cf. Peters 1991, Ch. 5; Sagoff, 2003, p. 532; Simberloff, 1980, pp. 23-5). Certain, more specific, critiques engage a literalist interpretation according to which a wellspring of alleged problems for ecologists is that they cannot "find a source for the teleology that [allegedly] underwrites [their] functional accounts" of ecological phenomena (Cooper, 2007, p. 282). For example, lauded environmental philosopher Mark Sagoff employs a literalist interpretation of teleological characterizations to found arguments according to which theoretical ecological research is supposed to be unscientific and of no use practical decision-making (see Sagoff 1997; 2000;

2013). For instance, in a recent popular article, he contends that much work in ecology is 
unscientific because modern ecologists still rely on some form of Clementian organicism (discussed above in \$1). ${ }^{10}$ Specifically, Sagoff alleges that ecologists rely on the claim that properties of ecological networks and their component parts are caused by some essential network-level telos or 'directed self-organizing capabilities.' And he argues that because there is, in his words, "magical thinking behind the idea that ecosystems are [...self-organizing] systems," ecologists cannot empirically substantiate that theories and models that characterize natural ecosystems are useful for characterizing any particular things in nature (Sagoff, 2013, p. 248 see also Sagoff, 1997, pp. 960-3, 891-3).

While I agree that there is no reason to think that ecological networks have properties that coordinate the behaviors of their component parts, I believe most modern ecologists would agree as well and submit that literalist construals of most teleological characterizations found in modern ecological research are misguided. I have lent credence to this claim already by recounting how ecologists traded robust ontological positions for an ontology-neutral one, according to which population, communities, and ecosystems, are simply causal networks resulting from contingent species-typical interactions, by the mid-1940s. I've also challenged the idea that modern ecologists rely on teleological metaphysics by arguing that Hutchinson did not do this even in the first, and in important ways archetypical, project in modern theoretical ecology; as well as by further arguing that ecologists routinely use teleological metaphors to aid in generating component-to-component accounts of the mechanics of ecological network-level dynamics following Hutchinson.

Since my story so far leaves off in 1948, with Hutchinson's project, one might well retort that ecologists could have systematically misinterpreted Hutchinson since the 1950s, forgotten about his metaphorical usage of teleological characterizations, or just plain reclaimed the robust teleological thinking of earlier ecologists. Notably, however, there is textual evidence showing that

\footnotetext{
10 I say that Sagoff's 2013 target article is "popular" on the grounds that it is listed as the "most read" article on the publishers main page (with over two-thousand reported views) and is cited in numerous independent published works.
} 
this apparently did not occur, and that, in general, ecologists have stayed on board with the idea that teleological characterizations of ecological phenomena are non-literal.

For one thing, the literature shows contemporary ecologists typically identifying bona fide teleological causes only at the level of individual organisms. Specifically, it shows that they appear to see such causes playing an operative role in bringing about ecological network-level properties only via the intentional reproductive and survival behaviors of individual organisms (cf. Irwin 2015, pp. 317-8; cf. McShea 2012). Since the most basic causally operative nodes in the networks they study are organisms, ecologists naturally take note of teleological causes when taking account of certain behaviors of particular organism(s). For instance, a wolf has a goal that determines its behavior when it preys upon deer, and explanations or predictions that account for individual wolf behaviors, or even pack behaviors, may therefore in some sense take account of the causal impacts of such goals. Yet, acknowledging that any organism may contribute to a series of ecological interactions that influence population, community, or ecosystem-level dynamics with some of its goal-directed behaviors in no way implies that the behaviors of individual organisms are also coordinated by some telos belonging to the ecological networks in which they are nodes (see Peacock, 2011, p. 235). Accordingly, I think most ecologists would agree that teleological causes are apparently operative only at the organism level of analysis (where one finds individuals with intentions). As Peter Richerson says:

Natural selection is the most basic ecological process because it appears to be the only mechanism directly responsible for goal-directed behavior on the part of biological organisms. In the past, ecologists have often carelessly attributed goal-seeking behavior to various levels of organization in what might now be characterized as 'fallacies of misplaced teleology.' (1977, p. 3)

The literature also shows that ecologists have tended to shy away from committing to any robust metaphysics at all. Numerous ecologists have defended antirealist positions, and numerous authors argue that a thoroughgoing antirealism has been the prevailing paradigm within ecology for 
several decades (see Botkin 1990; Fitzsimmons 1999; Wittbecker 1990). More generally, ecologists have shifted away from reifying descriptions of populations, communities, and ecosystems in the contemporary literature, toward talk of abstract 'levels of analysis.' In line with this shift, one often finds descriptions of ecological research as consisting in doing "network analyses" and investigating "network pathways," or series of stochastic interactions between organisms and aspects of their environment(s), that produce patterns observable at different network-levels of analysis (see Allesina \& Bondavalli 2004; REMOVED FOR REVIEWb; Patten 2010; Scharler et al 2005; Ulanowicz 2011). Prima facie robust teleological characterizations like the interconnection of everything to everything else' and 'self-organization' are considered accordingly as, "semantic constructs for describing the subtle and yet complex nature of eco[logical networks]" (Gattie et al 2006, p. 162; see also the sources cited therein). In other words, such characterizations are typically seen as useful ways of describing dynamic trends and patterns seen from a zoomed out, network-level, perspectiveor ways of outlining "very general events [that] are only seen [...] with rather blurred vision" as Robert MacArthur once said (1968, p. 159).

While much loose teleological language is undoubtedly very common in the ecological literature, one simply does not find evidence of a general shift back to serious commitments to a robust teleology. The burden is therefore on those who claim that modern ecologists' rely on teleological metaphysics, or any sort of "magical thinking," to provide anything but misinterpreted metaphors to uphold their critiques. To do a bit more than just offloading the burden of proof, I will now show that ecologists needn't rely on such commitments by outlining a viable deflationary, etiological and instrumentalist, view available to them. More specifically, I will finish out this section by sketching three lines of argument ecologists can use to defuse claims that their teleological characterizations commit them to a teleological metaphysics. 
My primary suggestion is that they can defuse such claims by explicitly embracing what I call an 'etiological' view of teleology. As I said in the introduction, this etiological view sees teleological characterizations as shorthand ways of describing the component-to-component underlying causes of ecological network-level properties. Whereas the robust teleological metaphysics some mistakenly attribute to ecologists assumes that some properties of ecological network's and their component part's are caused, “top-down," by a network's tendency to evolve toward some future state, an etiological metaphysics assumes that all properties are caused by component-to-component, "bottom-up," interactions. This view, which I believe is in fact generally received by modern ecologists, then effectively reduces teleological explanations to efficient causal explanations; in stark contrast to a teleological metaphysics that counts teleological explanations as genuine causal explanations that are somehow irreducible to efficient causal explanations. ${ }^{11}$

More specifically, I submit that teleological characterizations reduce to the following form according to the etiological understanding I am endorsing. They say that for any instance of some type of ecological network, $\mathrm{N}$ : 'any $\mathrm{N}$ has the function of doing $\mathrm{P}$ just in case an $\mathrm{N}$ is present as a result of causing P' (cf. Papineau, 1992, pp. 61-7; Wright, 1976, Ch. 3). Consider, for example, the characterization according to which an ecosystem is 'an ecological network that functions to maximize energy available for work within its boundaries to the extent permitted by energy inputs to that network' (see Mitsch \& Jørgensen, 2004, p. 92; Zhang et al., 2010, p. 695). This is to say that an ecosystem is present just in case an ecological network is functioning as such, and that that ecosystem persists just as long as that network continues to function that way. This etiological way of interpreting teleological characterizations of ecosystems does not require that one refer to any

\footnotetext{
11 The endorsed etiological view, which sees teleological claims as metaphorical characterizations of component-tocomponent causal processes, also appears to stand as an alternative to views that attempt to "naturalize" claims about teleological functions. Views of this later sort essentially claim that biological entities exhibit certain properties because they have "traits" (some type of composition) that has been designed for realizing said properties by evolutionary processes; see Bedau (1991) for discussion. I mention this to block confusions that may be triggered by my use of 'etiological,' which appears in the philosophical literature on "naturalizing teleological functions."
} 
teleological cause of the dynamics of any such networks. Rather, it sees the characterization according to which 'ecosystems function to maximize exergy' as telling one what an ecological network will do if it qualifies as an ecosystem, not why or how it may do it.

According to this etiological understanding, to say that a particular ecological network is an ecosystem because it exhibits exergy-maximizing dynamics is not to say that this fact explains why or how said network does so. It is just to say that the component parts of that network are, for the duration of that time they constitute an ecosystem, exhibiting patterns of behavior relative to each other such that they effectively maximize exergy within the boundaries of that network (whyever, however, and for whatever period of time they do so) (cf. Patten \& Odum, 1981, p. 889). Explicitly endorsing this etiological understanding of teleological characterizations, which I submit is at work in the background of contemporary work in ecology, would go a long way toward defusing allegations that ecologists still harbor commitments to antiquated teleological views.

Another way ecologists can effectively undermine claims that they embrace a teleological metaphysics is by more consistently noting that the "mechanisms" that produce ecological networklevel dynamics are identical to those operative in processes of natural selection. For example, it should be made clearer in the literature in ecology that processes of natural selection produce changes in the composition of ecological networks such that they exhibit network-level dynamics whose trajectories are aptly outlined with certain teleological characterizations. Consider, for instance, how processes of natural selection might change the composition of a community comprised of different plant species. A species, X, suited to growing well given an abundant supply of certain nutrients will do so and will therefore out-compete other species that are less well suited to growing in those same conditions. Accordingly, if relative nutrient resource abundances change substantially, species-X would likely be supplanted by a species, $\mathrm{Y}$, that is better suited to thriving in the new conditions. In this way, at least some community-scale plant networks do in fact "maximize 
useable energy" within their boundaries through processes whereby the most fit species always win the day-such that these communities always produce what can be described as an "optimal" amount of biomass by changing in their overall composition in response to changing network inputs. So, it just makes sense that the dynamics of any such network will be aptly characterized by saying that that network will exhibit compositional and structural changes in such a way that it will tend to maximize useable energy within its boundaries to the extent permitted by environmental constraints. ${ }^{12}$ Clearly explaining such things in the ecological literature would, in the very least, serve to make it clearer that ecologists' teleological characterizations are non-literal, and non-causal, and can be re-cast in component-to-component terms.

Finally, and perhaps obviously, ecologists can also undermine claims that they embrace a teleological metaphysics by explicitly committing to an 'instrumentalist' epistemology, according to which characterizations of ecological phenomena are essentially conceptual instruments whose value primarily depends on whether (and how well) they aid in understanding and predicting things about natural phenomena-regardless of whether they are true. This is not to suggest that commitment to an instrumentalist epistemology is implied by committing to the view that teleological characterizations are metaphorical. Indeed, one can maintain that characterizations of ecological networks are metaphorical and consistently maintain that they also, at least partially, accurately describe natural phenomena. My point is simply that instrumentalism is a tenable epistemology available to ecologists that is neutral with respect to matters of metaphysics. Hence, ecologists can also deflect claims that their teleological characterizations are literal by explicitly embracing a form of instrumentalism.

Worse for those who claim ecologists embrace any sort of robust metaphysics, as a matter of fact, instrumentalism appears to be the working epistemology of very many projects in ecology.

\footnotetext{
${ }^{12}$ One should also expect observable population abundance "oscillations" (as shown in Figure 1 above) in ecological networks in which nutrient levels change in periodic cycles (due to seasonal weather conditions, for instance).
} 
The express purpose of a large number of archetypal theoretical projects in ecology is developing maximally simplistic and predictively powerful principles and models-without concern for whether those, often patently false models, accurately represent things as they are in nature (REMOVED FOR REVIEWa; see also, Levins, 1966 and Odenbaugh, 2005). And since much current work in ecology aims to address environmental problems, is therefore solution-oriented and pragmatically driven, and increasingly "occurs in a volatile juncture between science and politics," one should expect that ecologists would naturally embrace broadly instrumentalist views (Odenbaugh, 2010, p. 155). For that matter, many would urge that ecological research is not, and perhaps has never been, geared toward developing literally true theories and models at all. In fact, numerous authors contend that the entire enterprise of ecology is best understood as an endless pragmatic effort to: posit new hypotheses that become relevant to public policy and resource management as the environment continually changes; anticipate novel environmental problems; and explore the potential ramifications of alternative responses to potential problems (cf. Holling, 1995, p. 4; Mitchell 2009, p. 99; Rist et al, 2013).

\section{Conclusion}

I have sought to push forward the philosophical and broader crossdisciplinary dialogue about ecology's scientific and practical value by clearing away some persisting confusions about the science's philosophical foundations. To take stock, I have done this by:

- tracking early ecologists' shift away from teleological metaphysics, and explaining the conceptual innovations that marked the beginning of modern theoretical ecology;

- offering an operational account of the heuristic role of teleological metaphors in certain general reasoning processes employed in theoretical ecological research (after Hutchinson 1948);

- challenging enduring literalist construals of teleological characterizations employed in ecology;

- and showing that ecologists needn't rely on robust teleological commitments by outlining etiological and instrumentalist views as viable alternatives. 
Of course, I have left much undone, and there remains much work to be done to glean further insights into ecology's foundations, inferential methods, and value. For example, though I have limited my attention to examining how we should understand teleological language in ecology, I believe the etiological view that I have outlined bears significant implications for concerns about ecologist's delineations of natural kinds of ecological phenomena. There is also interesting philosophical work to do on the implications of ecological research for general metaphysics and epistemology of science; as well as important practical work to do on clarifying applications of various ecological research methods for policy and resource management decision-making. It is my sincere hope that my arguments in this essay will inspire further work on ecology, and that others interested in ecology and its applications find resources in it to extend their own investigations.

\section{ACKNOWLEDGMENTS}

This work has benefited enormously from comments from three anonymous reviewers. And I must thank REMOVED FOR REVIEW. Last, I am grateful for the support received from the National Science Foundation (Grant No. REMOVED FOR REVIEW) during the development of some portions of this work.

\section{WORKS CiTED}

Allesina, S., \& Bondavalli, C. (2004). WAND: An ecological network analysis user-friendly tool. Environmental Modelling \& Software, 19(4), 337-340.

Apitz, S.E., Elliott, M., Fountain, M., \& Galloway, T.S. (2006). European environmental management: moving to an ecosystem approach. Integrated environmental assessment and management, 2(1), 80-85.

Bedau, M. (1991). Can biological teleology be naturalized? Journal of Philosophy 88, 647-57.

Botkin, D. B. (1990). Discordant harmonies: a new ecology for the twenty-first century: Oxford University Press.

Church, M, Hassan, MA, \& Wolcott, JF. (1998). Stabilizing self-organized structures in gravel-bed stream channels: field and experimental observations. Water Resources Research, 34(11), 3169-3179.

Clarke, GL. (1954). Elements of Ecology. New York: John Wiley

Clements, FE. (1916). Plant succession: an analysis of the development of vegetation: Carnegie Institution of Washington.

Colyvan, Mark, Linquist, Stefan, Grey, William, Griffiths, Paul E, Odenbaugh, Jay, \& Possingham, Hugh P. (2009). Philosophical issues in ecology: recent trends and future directions. Ecology and Society, 14(2), 22.

Cooper, G.J. (2007). The science of the struggle for existence: on the foundations of ecology: Cambridge University Press.

de Laplante, K., \& Picasso, V. (2011). The Biodiversity-Ecosystem Function Debate in Ecology. In K. de Laplante, B. Brown \& K. Peacock (Eds.), Pbilosophy of Ecology (pp. 169-200): Elsevier. 
Eaton, BC, Church, M, \& Davies, TRH. (2006). A conceptual model for meander initiation in bedload-dominated streams. Earth Surface Processes and Landforms, 31(7), 875-891.

Egerton, Frank N. (2012). Roots of Ecology: University of California Press.

Eliot, C. (2011). The legend of order and chaos: Communities and early community ecology, K. deLaplante, B. Brown, KA Peacock (Eds.), Handbook of the Philosophy of ecology, Elsevier, Oxford, 49-108.

Elton, C. (1927). Animal Ecology. Sidgwick \& Jackson, LTD, London.

EPA. (2002). A Framework For Assessing and Reporting on Ecological Condition: An SAB Report. (EPA-SAB-EPEC-02-009).

Fitzsimmons, A.K. (1999). Defending illusions: federal protection of ecosystems: Rowman \& Littlefield.

Fretwell, Stephen D. (1975). The impact of Robert MacArthur on ecology. Annual Review of Ecology and Systematics, 6(1), 113.

Gattie, D., Schramski, J., Borrett, S., Patten, B., Bata, S., \& Whipple, S. (2006). Indirect effects and distributed control in ecosystems. Ecological Modelling, 194(1-3), 162-177.

Gause, Georgii Frantsevich. (1932). Experimental studies on the struggle for existence I. Mixed population of two species of yeast. Journal of experimental biology, 9(4), 389-402.

Gleason, HA. (1939). The individualistic concept of the plant association. American Midland Naturalist, 21(1), 92-110.

Gleason, Henry Allan. (1917). The structure and development of the plant association. Bulletin of the Torrey Botanical Club, 463-481.

Goldsmith, Edward. (2008). The way: An ecological world-view: University of Georgia Press.

Golley, FB. (1993). A bistory of the ecosystem concept in ecology: more than the sum of the parts: Yale University Press.

Hall, C. A. (1988). An assessment of several of the historically most influential theoretical models used in ecology and of the data provided in their support. Ecological Modelling, 43(1), 5-31.

Haskell, Edward F. (1940). Mathematical Systematization of "Environment," “Organism” and "Habitat". Ecology, 21(1), $1-16$.

Holling, CS. (1995). What barriers? What bridges. Barriers and bridges to the renewal of ecosystems and institutions. Columbia University Press, New York, New York, USA, 3-34.

Hutchinson, GE. (1948). Circular Causal Systems in Ecology. New York. Academy Sciences Annals, 50, 221-246.

Hutchinson, George Evelyn. (1979). The kindly fruits of the earth: Recollections of an embryo ecologist. Yale University Press New Haven, CT.

Irwin, M. (2015). Evolutionary Analysis in Clasical and Neoclassical Human Ecology. In A. Maryanski, R. Machalek \& J. H. Turner (Eds.), Handbook on Evolution and Society (pp. 316-332): Routledge.

Jax, K., Jones, C. G., \& Pickett, S. T. (1998). The self-identity of ecological units. Oikos, 253-264.

Jordan, CF. (1981). Do Ecosystems Exist? American Naturalist, 118(2), 284-287.

Jørgensen, S.E. (2006). An Integrated Ecosystem Theory. Annual European Academy of Sciences, 19-33.

Keller, Evelyn Fox. (2008). Organisms, machines, and thunderstorms: A history of self-organization, part one. Historical Studies in the natural Sciences, 38(1), 45-75.

Kingsland, Sharon E. (1995). Modeling nature: University of Chicago Press.

Lange, M. (1994). Dispositions and Scientific Explanation. Pacific Philosophical Quarterly, 75, 108-132.

Levins, R. (1966). The strategy of model building in population biology. American Scientist, 54(4), 421-431.

Lindeman, Raymond L. (1942). The trophic-dynamic aspect of ecology. Ecology, 23(4), 399-417.

Lotka, AJ. (1925). Elements of Physical Biology. Baltimore: Williams \& Wilkins Company.

MacArthur, Robert H. (1957). On the Relative Abundance of Bird Species. Proceedings of the National Academy of Sciences of the United States of America, 43(3), 293-295. 
MacArthur, R. H. (1968). The Theory of the Niche. In R. C. Lewontin (Ed.), Population Biology and Evolution: Syracuse University Press.

McAfee, B., \& Malouin, C. (Eds.) (Eds.). (2008). Implementing Ecosystem-based Management Approaches in Canada's Forests: Natural Resources Canada; Canadian Forest Service.

McFadden, KW, \& Barnes, C. (2009). The implementation of an ecosystem approach to management within a federal government agency. Marine Policy, 33(1), 156-163.

McGinty, K, Pipkin, J, \& Gelburd, D. (1995). The ecosystem approach: Healtby ecosystems and sustainable economies (Vol. 1): Interagency Ecosystem Management Task Force.

McIntosh, Robert P. (1985). The background of ecology: concept and theory: Cambridge University Press.

McShea, D. W. (2012). Upper-directed systems: a new approach to teleology in biology. Biology \& Pbilosophy, 27(5), 663684.

Mitchell, S. (2009). Unsimple Truths: Science, Complexity, and Policy: University Of Chicago Press.

Mitsch, W.J., \& Jørgensen, S.E. (2004). Ecological engineering and ecosystem restoration: John Wiley \& Sons.

Möbius, Karl August. (1877). Die Auster und die Austernwirthschaft. Verlag von Wiegandt, Hemple \& Parey.

Nissen, Lowell. (1983). Wright on Teleological Descriptions of Goal-Directed Behavior. Philosophy of Science, 151-158.

Novikoff, Alex B. (1945). The Concept of Integrative Levels and Biology. Science, 101(2618), 209-215. doi: $10.2307 / 1672950$

Odenbaugh, J. (2005). Idealized, inaccurate but successful: A pragmatic approach to evaluating models in theoretical ecology. Biology and Pbilosophy, 20(2), 231-255.

Odenbaugh, Jay. (2007). Seeing the forest and the trees: Realism about communities and ecosystems. Philosophy of Science, 74(5).

Odenbaugh, Jay. (2010). Philosophy of the environmental sciences. In P. D. Magnus \& J. Busch (Eds.), New Waves in Philosophy of Science (pp. 155-171): Palgrave Macmillan.

Odenbaugh, J. (2011a). Philosophical themes in the work of Robert H. MacArthur. K. deLaplante, B. Brown, KA Peacock (Eds.), Handbook of the Philosophy of ecology, Elsevier, Oxford, 109-128.

Odenbaugh, J. (2011b). True Lies: Realism, Robustness, and Models. Pbilosopby of Science, 78(5), 1177-1188.

Odum, Eugene P. (1959). Fundamentals of Ecology (2nd edition) (2nd ed.): Saunders.

O’Neill, R. V. (2001). Is it time to bury the ecosystem concept? Ecology, 82(12), 3275-3284.

Papineau, D. (1992). Irreducibility and teleology. In Charles \& Lennon (Eds.), Reduction, Explanation, and Realism (pp. 4568): Clarendon Press.

Patten, B. (2010). Environs, eco-systems, and ecosystems: reply to a critique of Ecosystems Emerging, Comment on D. Schizas, G. Stamou [Ecol. Model.(2010)]. Ecological Modelling, 221, 1636-1643.

Patten, Bernard C., \& Odum, Eugene P. (1981). The Cybernetic Nature of Ecosystems. The American Naturalist, 118(6), 886-895.

Peacock, K. (2011). Symbiosis in Ecology and Evolution. In K. de Laplante, B. Brown \& K. Peacock (Eds.), Pbilosophy of Ecology: Elsevier.

Peters, R.H. (1991). A critique for ecology: Cambridge University Press.

Reiners, W. A., \& Lockwood, J. A. (2010). Philosophical Foundations for the Practices of Ecology: Cambridge University Press.

Richerson, P. J. (1977). Ecology and Human Ecology. American Ethnologist, 4(1), 1-26.

Rist, Lucy, Campbell, Bruce M, \& Frost, Peter. (2013). Adaptive management: where are we now? Environmental Conservation, 40(01), 5-18.

Sagoff, M. (1997). Muddle or muddle through? Takings jurisprudence meets the Endangered Species Act. William and Mary Law Review, 38(3), 825-993. 
Sagoff, M. (2000). Ecosystem design in historical and philosophical context. In D. Pimentel, L. Westra \& R. Noss (Eds.), Ecological integrity: integrating environment, conservation, and health (pp. 61-78): Island Press.

Sagoff, M. (2003). The plaza and the pendulum: Two concepts of ecological science. Biology and Pbilosophy, 18(4), 529-552.

Sagoff, M. (2013). What does environmental protection protect? Ethics, Policy, and Environment, 16(3), 239-257.

Scharler, U. M., \& Baird, D. (2005). A comparison of selected ecosystem attributes of three South African estuaries with different freshwater inflow regimes, using network analysis. Journal of Marine Systems, 56(3), 283-308.

Shrader-Frechette, Kristin. (1986). Organismic biology and ecosystems ecology. In N. Rescher (Ed.), Current Issues in Teleology (pp. 77-92): University Press of America.

Shrader-Frechette, KS, \& McCoy, ED. (1993). Method in ecology: strategies for conservation: Cambridge Univ Pr.

Simberloff, D. (1980). A succession of paradigms in ecology: essentialism to materialism and probabilism. Synthese, 43(1), 3-39.

Slack, Nancy G. (2011). G. Evelyn Hutchinson and the invention of modern ecology: Yale University Press.

Sole, R., \& Bascompte, J. (2006). Self-Organization in Complex Ecosystems: Princeton University Press.

Sterelny, Kim. (2001). The reality of ecological assemblages: A palaeo-ecological puzzle. Biology and Philosophy, 16(4), 437461.

Tansley, A.G. 1935. The Use and Abuse of Vegetational Concepts and Terms. Ecology 16(3), 284-307.

Ulanowicz, R. (1999). Life after Newton: an ecological metaphysic. BioSystems, 50(2), 127-142.

Ulanowicz, R. (2011). Quantitative Methods for Ecological Network Analysis and Its Application to Coastal Ecosystems. Treatise on Estuarine and Coastal Science, 9, 35-57.

UNFCC. (2013). Non-economic Losses in the Context of the Work Programme on Loss and Damage. from http://unfccc.int/resource/docs/2013/tp/02.pdf

Volterra, Vito. (1926). Fluctuations in the abundance of a species considered mathematically. Nature, 118, 558-560.

Volterra, V. (1927). Variazioni e fluttuazioni del numero d'individui in specie animali conviventi: C. Ferrari.

Voûte, AD. (1968). Ecology as a teleological science. Acta biotheoretica, 18(1), 143-164.

Wittbecker, A.E. (1990). Metaphysical Implications from Physics and Ecology. Environmental Ethics, 12(3), 276-281.

Worster, D. (1990). The ecology of order and chaos. Environmental History Review, 14(1/2), 1-18.

Wright, Larry. (1976). Teleological explanations: An etiological analysis of goals and functions: Univ of California Press.

Zhang, J., Gurkan, Z., \& Jorgensen, S.E. (2010). Application of eco-exergy for assessment of ecosystem health and development of structurally dynamic models. Ecological Modelling, 221(4), 693-702. 